\title{
2016 in Review and Message from the Editors to our Reviewers
}

\section{OPEN}

Stefan M. Pulst, MD, Dr med Editor

Nicholas Elwood Johnson, MD

Deputy Editor

Alexandra Durr, MD, $\mathrm{PhD}$

Massimo Pandolfo, MD, FAAN

Raymond P. Roos, MD, FAAN

Jeffery M. Vance, MD, $\mathrm{PhD}$ Associate Editors

Correspondence to Dr. Pulst:

stefan.pulst@hsc.utah.edu

Neurol Genet

2017;3:e132; doi: 10.1212/ NXG.0000000000000132
For this Helix, the editors of Neurology ${ }^{\circledR}$ Genetics have chosen some of their favorite articles of the past year. It is an eclectic collection drawing on different journals including Neurology: Genetics and varied topics.

Two articles report major advances in the understanding of how the C9orf72 GGGGCC repeat expansion exerts its pathogenic effect. ${ }^{1,2}$ This mutation is a major cause of familial amyotrophic lateral sclerosis (ALS) and frontotemporal dementia (FTD) as well as the cause of $5 \%-10 \%$ of what appears to be sporadic ALS. Understanding the molecular and cellular mechanisms of its pathogenicity is an essential step toward finding therapies for these devastating diseases. The work reported in these articles is remarkable as it identifies effects of both toxic RNA and repeat associated non-AUG (RAN)-translation products generated by this repeat and links them to pathogenic mechanisms shared by other ALS/FTDcausing mutations.

A landmark publication this year describes the generation and characterization of a C9orf72 bacterial artificial chromosome transgenic mouse. ${ }^{3}$ This mouse model will be important in helping to clarify the pathogenesis of ALS and FTD and can be used to explore the efficacy of potential treatments.

Two articles analyzed white matter changes in FTD due to GRN and C9orf72 mutations and in primary familial brain calcifications due to a novel PDGFB mutation. ${ }^{4,5}$ The white matter changes preceded atrophy/calcifications and could be a premanifest marker in primary familial brain calcification. White matter changes could therefore exacerbate the pathogenic cascades in neurodegenerative diseases characterized by motor and cognitive signs. These changes may include oligodendroglial dysfunction, as suspected for the $G R N$ haploinsufficiency. Extensive white matter changes are present also in mouse models of neurodegeneration, and effects of altered oligodendrocyte function on disease progression are suspected.

Adams et al. ${ }^{6}$ provide an example of how "crowdsourcing" data collection may provide enough power to detect genetic variants affecting normal variation as well as disease susceptibility. Combining data from many contributors allowed them to identify genetic variants affecting intracranial volume, strictly related to brain volume, which in turn affects the risk of cognitive impairment.

The use of gene therapy to treat peripheral neuropathies faces a number of challenges including ones related to delivery. A recent study describes rescue of an X-linked demyelinating form of CharcotMarie-Tooth disease (CMT1X) in gap junction beta 1 gene $(G J B 1)$ null mice, which lack connexin32 (CX32) protein. ${ }^{7}$ One intrathecal injection of a lentiviral vector expressing GJB1 gene under the control of the myelin protein zero $(M P Z)$ promoter led to stable and cell-specific expression of CX32 in up to $50 \%$ of Schwann cells in multiple lumbar spinal roots and peripheral nerves. The treated mice had improved motor function and electrophysiologic indices, as well as less pathology. The virus vector presumably diffused from the spinal fluid in the subarachnoid space into the epineurium of the peripheral nerve, demonstrating that this delivery route could be used in the treatment of other peripheral neuropathies.

Phuah et al. ${ }^{8}$ extended the clinical phenotype of $A P O E \varepsilon 4$ carriers, long known as the major risk factor for Alzheimer disease. They found that APOE $\varepsilon 4$ carriers had a significantly greater decline in serum total cholesterol and low-density lipoprotein in the 6 months preceding an intracerebral hemorrhage, relative to $A P O E \& 2$ carriers. $A P O E$ remains one of the most interesting genes in the CNS, and one of the most important. Despite being identified as a risk factor for Alzheimer disease in 1989, its function in that regard is still not fully understood. Mutations in the gene in humans and mice support its role in

From the Department of Neurology (S.M.P., N.E.J.), University of Utah, Salt Lake City; Hôpital de la Salpêtrière (A.D.), Paris, France; Hôpital Erasme (M.P.), Université Libre de Bruxelles, Belgium; University of Chicago Medical Center (R.P.R.); and University of Miami (J.M.V.), FL. Funding information and disclosures are provided at the end of the editorial. Go to Neurology.org/ng for full disclosure forms.

This is an open access article distributed under the terms of the Creative Commons Attribution-NonCommercial-NoDerivatives License 4.0 (CC BY-NC-ND), which permits downloading and sharing the work provided it is properly cited. The work cannot be changed in any way or used commercially without permission from the journal. 
lipoprotein metabolism. It is fascinating to note that almost 30 years after its rise to clinical importance, we continue to identify its association with major neurologic events.

An impressive multinational effort characterized the variability of dysferlin mutations, including symptoms and rate of progression of their associated disease. ${ }^{9}$ Missense mutations were a frequent cause of the disease. The characterization of the mutation, which may cause a spectrum of disease syndromes, is increasingly important in neuromuscular disease as novel therapeutics may be broadly applicable across phenotypes. Indeed, it is likely that the mutation (e.g., missense, nonsense, etc.) is more likely to select the therapeutic trial population rather than the phenotype. Additional, similar, studies in other limbgirdle muscular dystrophies are now possible as the Jain Foundation, Muscular Dystrophy Association, and other patient advocacy foundations have subsidized genetic testing for limb-girdle muscular dystrophies. These resources will extend the knowledge of the genotype-phenotype variability and offer a more accurate understanding of the prevalence of these conditions.

Genome-wide association studies have identified many risk variants, most of them not changing the coding sequence of a gene, but potentially regulating gene expression. Several DNA variants upstream of the SNCA gene encoding $\alpha$-synuclein have been identified, but their direct relationship to regulating SNCA expression was not known. Soldner et al. ${ }^{10(\mathrm{p} 1)}$ made use of a novel method to manipulate the genome, called CRISPR/Cas9, to delete or change specific sequences encompassing previously identified variants. They accomplished these genetic engineering feats in embryonic stem cells that they differentiated into neurons so that SNCA expression could be measured in the correct cell type. Indeed, the variant with the greatest associated risk for Parkinson disease increased SNCA expression in neurons.

The final selection does not directly relate to the nervous system, but is relevant in the context of neurogenetics, as it deals with the evaluation of DNA variants as causative for disease. The Kohane group examined variants that had previously been considered causal in hypertrophic cardiomyopathy. ${ }^{11}$ Variants that were falsely classified as pathogenic occurred predominantly in African Americans. Simulations showed that the inclusion of even small numbers of African Americans in control cohorts probably would have prevented these misclassifications, highlighting the importance of diversity in variant databases. The problem of erroneously assigning mutation status to rare, sometimes population-dependent benign DNA variants is widespread. It is of most actionable importance in the clinical arena, but as editors of Neurology: Genetics, we face similar challenges when deciding on acceptance of manuscripts reporting novel mutations in established disease-causing genes.

We wish to acknowledge the individuals who have completed reviews for the journal since its launch in April 2015. Your thoughtful comments are tremendously helpful and highly appreciated. We are also grateful for your cooperation in returning reviews in a timely manner. Please follow theguidelines for reviewing articles accessed by selecting the Information for Reviewers (IFR) link on the Neurology.org/ng website. The IFR provides information on expectations of reviewers regarding confidentiality, timeliness, and reviewer conflicts of interest; it also provides instructions for formatting the comments to editors and authors to enable the most effective communication with authors. Please email ngjournal@neurology.org if you would like to do more reviews or if you have never reviewed for the journal but are interested in doing so. Include a description of your credentials and expertise in the areas in which you are qualified to review. We look forward to hearing from you!

Our 2016 reviewers are listed at the end of this article.

\section{STUDY FUNDING}

No targeted funding reported.

\section{DISCLOSURE}

S.M. Pulst serves on the editorial boards of Journal of Cerebellum, NeuroMolecular Medicine, Continuum, Experimental Neurology, Neurogenetics, and Nature Clinical Practice Neurology and as Editor-in-Chief of Current Genomics; receives research support from NIH, Target ALS, National Ataxia Foundation, and ISIS Pharmaceuticals; has consulted for Ataxion Therapeutics; is a stockholder of Progenitor Life Sciences; has received license fee payments from Cedars-Sinai Medical Center; has given expert testimony for Hall \& Evans, LLC; holds multiple patents; and receives an honorarium from the AAN as the Editor of Neurology: Genetics. N.E. Johnson has served as Associate Editor for Neurology: Genetics; has consulted for AMO Pharma and AveXis; has received research support from Ionis Pharmaceuticals, Biogen Idec, Valerion Therapeutics, Cytokinetics, Acceleron, National Institute of Neurological Disorders and Stroke (1K23NS091511-01), Muscular Dystrophy Association and Myotonic Dystrophy Foundation. A. Durr has served on scientific advisory boards for INSERM (NIH and research), International Science Advisory Board of the Helmholtz Initiative on Personalized Medicine and Grenoble Neuroscience Institute; has served on the editorial boards of Journal of Huntington's Disease, Archives of Neurology; holds patents and receives royalties for Anaplerotic therapy of Huntington disease and other polyglutamine diseases; has received research support from CoEn. M. Pandolfo has served on scientific advisory boards for Apopharma, Voyager Therapeutics; has served on editorial boards of Acta Neurologica Belgica, Orphanet Journal of Rare Diseases, and as Associate Editor of Neurology: Genetics; holds patents and receives royalties for Direct molecular diagnosis of Friedreich's ataxia; has consulted for Biomarin and UCB; and has received research support from Biomarin, Fonds National de la Recherche Scientifique, Offrez-moi-la-lune, Friedreich's Ataxia Research Alliance, and Association Belge contre les Maladies neuro-Musculaires. R.P. Roos serves on the editorial board of Virology and MedLink. He 
conducts research supported by the NIH, the ALS Association, the Judith and Jean Pape Adams Charitable Foundation, the Ralph and Marian Falk Medical Research Trust Grant, and the Chicago Biomedical Consortium. $\mathrm{He}$ is a stockholder of Amgen, Merck, Ionis Pharmaceuticals, and Express Scripts. J.M. Vance has received funding for travel or speaker honoraria from NETPR, Department of Defense, and NIH; serves on the editorial boards of American Journal of Neurodegenerative Diseases and as Associate Editor of Neurology: Genetics; holds patents for method of detecting Charcot-Marie-Tooth disease type 2A, TRPC6 involved in glomerulonephritis, and methods for identifying an individual at increased risk of developing coronary artery disease; has received research support from NIH/National Institute of Neurological Disorders and Stroke and Hussman Foundation; and receives royalties from Duke University. Go to Neurology.org/ng for full disclosure forms.

\section{REFERENCES}

1. Freibaum BD, Lu Y, Lopez-Gonzalez R, et al. GGGGCC repeat expansion in C9orf72 compromises nucleocytoplasmic transport. Nature 2015;525:129-133.

2. Zhang K, Donnelly CJ, Haeusler AR, et al. The C9orf72 repeat expansion disrupts nucleocytoplasmic transport. Nature 2015;525:56-61.

3. Liu Y, Pattamatta A, Zu T, et al. C9orf72 BAC mouse model with motor deficits and neurodegenerative features of ALS/FTD. Neuron 2016;90:521-534.

4. Ameur F, Colliot O, Caroppo P, et al. White matter lesions in FTLD: distinct phenotypes characterize $G R N$ and C9ORF72 mutations. Neurol Genet 2016;1:e47. doi: 10.1212/NXG.0000000000000047.

5. Biancheri R, Severino M, Robbiano A, et al. White matter involvement in a family with a novel $P D G F B$ mutation. Neurol Genet 2016;2:e77. doi: 10.1212/ NXG.0000000000000077.

6. Adams HHH, Hibar DP, Chouraki V, et al. Novel genetic loci underlying human intracranial volume identified through genome-wide association. Nat Neurosci 2016;19:1569-1582.

7. Kagiava A, Sargiannidou I, Theophilidis G, et al. Intrathecal gene therapy rescues a model of demyelinating peripheral neuropathy. Proc Natl Acad Sci USA 2016;113: E2421-E2429.

8. Phuah CL, Raffeld MR, Ayres AM, et al. APOE polymorphisms influence longitudinal lipid trends preceding intracerebral hemorrhage. Neurol Genet 2016;2:e81. doi: 10. 1212/NXG.0000000000000081.

9. Harris E, Bladen CL, Mayhew A, et al. The Clinical Outcome Study for dysferlinopathy. Neurol Genet 2016;2: e89. doi: 10.1212/NXG.0000000000000089.

10. Soldner F, Stelzer Y, Shivalila CS, et al. Parkinson-associated risk variant in distal enhancer of $\alpha$-synuclein modulates target gene expression. Nature 2016;533:95-99.

11. Manrai AK, Funke BH, Rehm HL, et al. Genetic misdiagnoses and the potential for health disparities. $\mathrm{N}$ Engl J Med 2016;375:655-665.

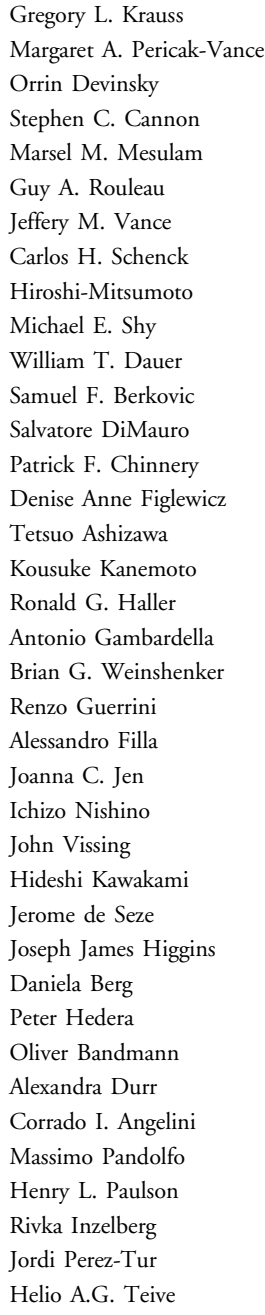

Anders Oldfors
Franco Antonio Laccone
Merit E. Cudkowicz
David N. Herrmann
Filippo M. Santorelli
John Hardy
Katrin Bürk
Gary Gronseth
Raymond P. Roos
Hidehiro Mizusawa
Huw R. Morris
Dominique Campion
Marina Fanin
Peter M. Andersen
Christine Van Broeckhoven
Olga O. Favorova
Matthew P. Wicklund
Massimo Zeviani
Iscia Lopes-Cendes
Cyril Goizet
Hyder Azad Jinnah
Carsten G. Bonnemann
Alexander G. Bassuk
Roberto De Simone
Alfredo Brusco
Garth A. Nicholson
Shoji Tsuji
Bart P.C. van de Warrenburg
Heather Adams
Liu Lin Thio
Orhun H. Kantarci
Tom Britton
Daniela Galimberti
Jennifer Juhl Majersik
Nicole I. Wolf
Hiroshi Takashima
Beldink
Herman Veld

Peter Huppke

Mary M. Reilly

Patricia Maciel

Margaret Elizabeth Ross

Christiane Reitz

Nobutaka Hattori

Brent L. Fogel

Shinichi Hirose

Elliott H. Sherr

John C. Carey

Susanne A. Schneider

Marcondes C. França Jr.

Marc W. Halterman

Geoffrey L. Heyer

Conrad Christian Weihl

Chantal M.E. Tallaksen

Pau Pastor

Owen A. Ross

Manu Sharma

Maite Mendioroz

Gabriella Silvestri

Antonio V. Delgado-Escueta

Margherita Milone

Sudha Seshadri

Alison M. Goate

David Q. Beversdorf

Roy N. Alcalay

Christopher M. Gomez

Wolfram S. Kunz

Jonathan Daniel Rohrer

Pawel P. Piotr Liberski

Henry Houlden

Giovanni Stevanin

Andrew H. Crosby

Shawn K. Westaway

Lee-Jun C. Wong

Andreas Puschmann

Naoki Suzuki

\author{
Mario Masellis \\ Renato Borgatti \\ Robert B. Weiss \\ Ulrike Schara \\ Wendy Gilmore \\ Roser Pons \\ William K. Scott \\ Marta San Luciano \\ John B. Moeschler \\ Mitsuhiro Kato \\ Simon Mead \\ Chantal Depondt \\ Marie Vidailhet \\ Dick Lindhout \\ Fanny Mochel \\ Emmanuelle Plaisier \\ Antonio Toscano \\ Michael C. Kruer \\ Jocelyn F. Laporte \\ Paul A. Nyquist \\ Nicholas E. Johnson \\ Michael Nalls \\ Han-Xiang Deng \\ Anne Ducros \\ A. James Barkovich \\ S. H. Subramony \\ Kathrin Brockmann \\ Ignacio F. Mata \\ Gerard D. Schellenberg \\ Marie-Christine Chartier-Harlin \\ Robert D.S. Pitceathly \\ Franziska Johanna Hopfner \\ Ellen Sidransky \\ Marka van Blitterswijk \\ John A. Damiano \\ Katell Peoc'h \\ Thomas Gasser \\ Sylvia M. Boesch
}


Heather C. Mefford

Stefan M. Pulst

Gianpiero Cavalleri

Kinya Ishikawa

Stephanie Baulac

Wilson Marques

Charlotte J. Sumner

Renaud Touraine

Sonja W. Scholz

Anna Bersano

Michael T. Heneka

Michael J. Chao

Timothy Lynch

Danielle M. Andrade

Jonathan L. Haines

Lars Bertram

Damien Sanlaville

Michael Farris Waters

Ammar Al-Chalabi

Cyril Mignot

Jennifer S. Yokoyama

Adriano Chio
Michel Willemsen

Kanwaljit Singh

Jason Lazarou

James J. Dowling

William D. Graf

Karen Nuytemans

Masharip Atadzhanov

Mohamad Mikati

Perry B. Shieh

Joseph Paul Taylor

Russell J. Butterfield

Ricardo Horacio Roda

Takayuki Kondo

Shakkottai G. Vikram

Cyrus Boelman

Stanley Iyadurai

Pasquale Striano

Satoshi Yamashita

Vera Fridman

Karla P. Figueroa

Tara M. Newcomb

Thomas E. Lloyd
Toni Pearson

Ingo Helbig

Angela Vincent

Andrea L. Gropman

Keith P. Van Haren

Salvador Soriano

Rainer Malik

Salvatore Spina

Steffan D. Bos

Jun Li

Jan Senderek

Lawrence Wrabetz

Ashutosh K. Mangalam

Liwen Wu

Edward C. Cooper

Noah Allan Kolb

Carly E. Siskind

Cinzia Coppola

Steven Estus

Timothy M. Shepherd

Rodolfo Savica

Rita J. Guerreiro
Jose M. Bras

Isaac Marin-Valencia

Marina Konakova

Stephanie Sherman

Julie R. Korenberg

Holly N. Cukier

Allison Ashley-Koch

David Viskochil

Fuki Marie Hisama

Stefano F. Cappa

Craig Blackstone

Donald S. McCorquodale

Susan Halloran Blanton

Maria do Carmo Costa

Goldie Smith Byrd

Josiah Leong

David G. Munoz

Anthony J. Griswold

Daniel Scoles

Alexandre de Mendonca

Kenneth Nakamura 


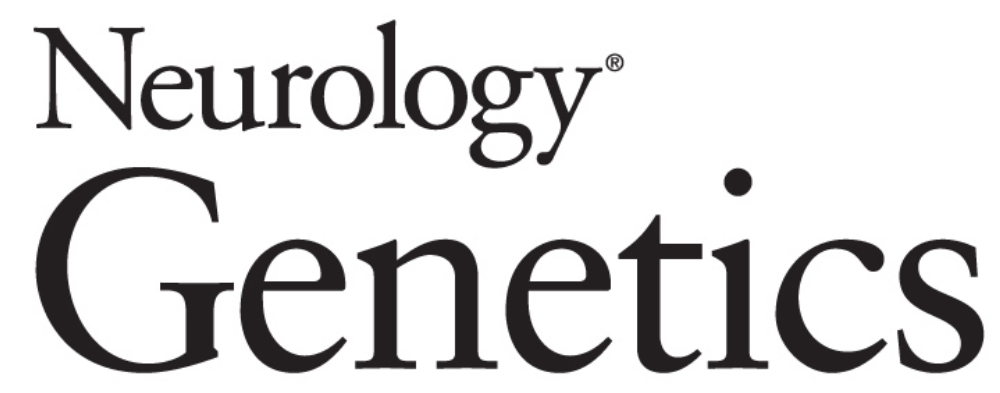

2016 in Review and Message from the Editors to our Reviewers

Stefan M. Pulst, Nicholas Elwood Johnson, Alexandra Durr, et al.

Neurol Genet 2017;3;

DOI 10.1212/NXG.0000000000000132

This information is current as of February 16, 2017

\section{Updated Information \&} Services

References

Permissions \& Licensing

Reprints including high resolution figures, can be found at: http://ng.neurology.org/content/3/1/e132.full.html

This article cites 11 articles, 4 of which you can access for free at: http://ng.neurology.org/content/3/1/e132.full.html\#\#ref-list-1

Information about reproducing this article in parts (figures,tables) or in its entirety can be found online at:

http://ng.neurology.org/misc/about.xhtml\#permissions

Information about ordering reprints can be found online: http://ng.neurology.org/misc/addir.xhtml\#reprintsus

Neurol Genet is an official journal of the American Academy of Neurology. Published since April 2015, it is an open-access, online-only, continuous publication journal. Copyright Copyright @ 2017 The Author(s). Published by Wolters Kluwer Health, Inc. on behalf of the American Academy of Neurology. All rights reserved. Online ISSN: 2376-7839.

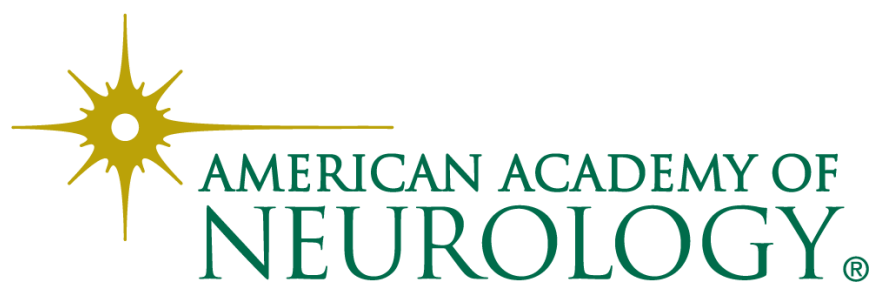

